Tropical Journal of Pharmaceutical Research July 2017; 16 (7): 1489-1496

ISSN: $1596-5996$ (print); 1596-9827 (electronic)

(C) Pharmacotherapy Group, Faculty of Pharmacy, University of Benin, Benin City, 300001 Nigeria.

All rights reserved.

Available online at http://www.tjpr.org

Original Research Article

http://dx.doi.org/10.4314/tjpr.v16i7.5

\title{
Formulation and characterization of caffeine biodegradable chewing gum delivery system for alertness using plasticized poly(D,L-lactic acid) as gum base
}

\author{
Farhad Firoze Mehta*, R Rajagopalan and Piyush Trivedi \\ Department of Pharmaceutics, School of Pharmaceutical Sciences, Rajiv Gandhi Technological University, Bhopal (M.P.), India
}

*For correspondence: Email: mehta.farhad@gmail.com; Tel: +91-9893055516

Sent for review: 16 December 2016

Revised accepted: 12 June 2017

\begin{abstract}
Purpose: To formulate and evaluate biodegradable plasticized poly(D,L-lactic acid) as a base for caffeine-medicated chewing gums (MCGs) to increase alertness.

Methods: Biodegradable plasticized poly(D,L-lactic acid) caffeine-MCGs were formulated with a fixed concentration $(15 \% \mathrm{w} / \mathrm{w})$ of different plasticizers for different formulations. Substances used as plasticizers were triacetin, stearic acid, PEG-600, tributyl citrate, soya oil, sunflower oil, glycerol, triethyl citrate, PEG-4000, and castor oil. The characteristics of the gum formulations were examined using texture profile analysis (TPA), and also evaluated for biodegradation, microstructure', in vitro drug release, and sensory features.

Results: The MCG-1 and MCG-7 formulations with triacetin and glycerol as plasticizers, respectively, exhibited a biodegradation score of 1 and 2, respectively, indicating considerable biodegradation. The formulation with triacetin as a plasticizer exhibited TPA values of $3750.52 \mathrm{~g},-51.13 \mathrm{~g} \cdot \mathrm{s}, 1580.88$, 1526.23, and 0.364 for hardness, adhesiveness, gumminess, chewiness, and cohesiveness, respectively; these values are similar to those of the Military Energy Gum. The microstructure of the gum base was characterized using scanning electron microscopy to determine surface properties. The in vitro drug release was determined as $97 \%$ after a mean chewing time of 15 min by using a specially designed in vitro chewing machine.

Conclusion: Plasticized poly ( $D, L$-lactic acid) gum formulation is suitable for the delivery of caffeine and can be used as an alternative MCG for effective management of fatigue.
\end{abstract}

Tropical Journal of Pharmaceutical Research is indexed by Science Citation Index (SciSearch), Scopus, International Pharmaceutical Abstract, Chemical Abstracts, Embase, Index Copernicus, EBSCO, African Index Medicus, JournalSeek, Journal Citation Reports/Science Edition, Directory of Open Access Journals (DOAJ), African Journal Online, Bioline International, Open-J-Gate and Pharmacy Abstracts

\section{INTRODUCTION}

Chewing gums are considered as one of the popular drug delivery methods because they are easy to use, do not require water, have a good taste, and are liked by children. A medicated chewing gum (MCG) is defined by European Pharmacopeia [1] as a 'solid single dose preparation with a base mainly consisting of gum, which is intended to be chewed but not swallowed [2]'. The action of the drug delivered through chewing gums is rapid because the permeable and blood-rich oral mucosa quickly absorbs the active substances, which subsequently pass through the jugular veins directly into the blood $[3,4]$. Conventional chewing gums are formulated using synthetic or natural elastomers. The synthetic or natural elastomers in gum cuds have an adhesive-like character, which enables them to adhere to any surface if not properly discarded. To overcome the stickiness problem, biodegradable chewing gums based on poly(lactic acid-co-caprolactone) elastomers and plasticized poly(D,L-lactic acid) have been formulated in US Patent no.5672367 [5] and 6613363 [6], respectively. Such MCGs 
are currently widely accepted in oral healthcare [7].

MCGs contain active drug ingredients either in a gum base or sweetened coating. However, the load of active substances and rate of release must be fine-tuned for each product; some drug ingredients have an unpleasant, bitter, or metallic taste [8]. For agents used in systemic delivery, MCG is the preferred delivery method [9].

Caffeine, a central nervous system stimulant, is an odourless white crystalline xanthine alkaloid, which inhibits the phosphodiesterase enzyme and has an antagonistic effect on the central adenosine receptor $[10,11]$. Adenosine is produced in the body during energy-consuming activities and binds to the adenosine receptors, leading to restlessness and fatigue. To counter the effect of adenosine, caffeine binds to the adenosine receptor and prevents its signalling to increase alertness [10,11]. Caffeine serves as a key component in various beverages such as tea, coffee, carbonated soft drinks, and energy drinks, which are very popular among people. Moreover, the formulation of caffeine chewing gums with synthetic ingredients and sugar-free coating and the organoleptic characterization of 20 and $50 \mathrm{mg}$ caffeine gums were reported by Aslani et al [11]. The present study evaluated plasticized poly(D,L-lactic acid) biodegradable caffeine MCG for effectively managing fatigue.

\section{EXPERIMENTAL}

\section{Ingredients}

Poly(D,L-lactic acid) powder with $M_{w} 18,000$ 28,000 was used as a bulking agent to prepare plasticized poly(D,L-lactic acid) chewing gums, and the gum former was purchased from SigmaAldrich (India) Private Limited. Talc, ester gum, and beeswax were purchased from C.D.H. (New Delhi, India). Photoactive titanium dioxide used as a filler was purchased as solid flakes from Smart Nanoz Private Limited (Pune, India). Distilled monoglycerides used as an emulsifier was purchased from Estelle Private Limited (Maharashtra) in liquid form; granular peppermint flavour was purchased from Glee Gum Kit (USA); Triacetin, PEG-600, tributyl citrate, soya oil, sunflower oil, glycerol, and triethyl citrate used as plasticizers were purchased from C.D.H. (New Delhi, India). Stearic acid and PEG-4000 used as plasticizers were purchased from C.D.H. (New Delhi, India) as a white powder and solid flakes, respectively. Xanthum gum used as a binder was purchased from C.D.H. (New Delhi, India) in powder form. Sugar alcohols malitol and sorbitol used as sweeteners were purchased from C.D.H.
(New Delhi, India) in solid powder form. Xylitol and neotame used as artificial sweeteners were obtained as a gift sample from J.J.D. Enterprises (Ghaziabad, UP, India). Caffeine was purchased from HiMedia Laboratories Pvt. Limited (Nasik, Maharashtra, India).

\section{Preparation of biodegradable plasticized poly(D,L-lactic acid) chewing gum}

Biodegradable plasticized poly(D,L-lactic acid) chewing gums were prepared using a modified method recommended by Li et al [6]. In brief, a laboratory sigma blade mixer $(1 \mathrm{~kg})$ with a front to rear speed ratio of $2: 1$ was preheated at $80^{\circ} \mathrm{C}$, and the gum base poly(D,L-lactic acid), plasticizer, and photoactive titanium dioxide were added to it. By using different types of plasticizers, different formulations of poly(D,Llactic acid) chewing gum samples were prepared. After 15 min of mixing, talc and ester gum were slowly added by continuously mixing the polymer for 5 more min. Subsequently, beeswax and distilled monoglycerides were added and mixed using z-shaped blades of the sigma blade mixer with continuous stirring for $30 \mathrm{~min}$. The ingredients were further kneaded for $15 \mathrm{~min}$ by using the blender. Later, the gum base was spread using a roller into a thin sheet, cut into 10$\mathrm{g}$ strips, and stored at room temperature.

Poly(D,L-lactic acid) synthetic biodegradable chewing gums were prepared with $(15 \% \mathrm{w} / \mathrm{w})$ of either triacetin, stearic acid, PEG-600, tributyl citrate, soya oil, sunflower oil, glycerol, triethyl citrate, PEG-4000, or castor oil as a plasticizer. Photoactive titanium dioxide (15\% w/w), talc, and ester gum $(10 \% \mathrm{w} / \mathrm{w})$ were used as bulking agents. Beeswax and distilled monoglycerides $(7.5 \% \mathrm{w} / \mathrm{w})$ were used as emulsifiers in the formulation.

\section{Coating of plasticized poly(D,L-lactic acid) chewing gum}

The plasticized poly(D,L-lactic acid) chewing gum was coated with a sweetener and corn syrup, and the mixture was heated at $60^{\circ} \mathrm{C}$ for 15 min and allowed to mix uniformly [12]. The sweetener blend was prepared by mixing sugar alcohols such as mannitol and sorbitol, artificial sweeteners such as neotame and xylitol, and a binder such as xanthan gum. Gum pieces were dipped in the coating solution, and a dry powder material (sweetener) was applied after $1 \mathrm{~min}$ ensuring that the liquid evenly covered the pieces. This process helped to dry the liquid coating and is referred to as dry charging $[12,13]$. A total of $10 \mathrm{mg}$ of caffeine was preblended with the dry charge material and 
peppermint flavour. The dry charge material was covered using a few liquid applications, and subsequently, the coating was dried in a hot air oven with temperatures ranging from 25 to 35 ${ }^{\circ} \mathrm{C}$. To coat MCG, six coating solutions with different sweetener concentrations (1 - $6 \%$ w/w) were used.

The gum pieces were rolled on the coating solution containing the sweetener and then dipped in the coating solution to make the coating even. Subsequently, the gum pieces were placed on a glass dish covered with a plastic wrap in a refrigerator.

\section{Coating firmness determination}

To determine the firmness of the coating solution, a TA.XT Express Enhanced Texture Analyser (Stable Micro Systems, Godalming, Surrey, UK) was used. To record and analyse the results, the Exponent Light Express software (version 5.1.1.1, Stable Micro Systems), was used. Macros were used in the software to calculate the variables and parameters, and the data was further analysed in MS Excel.

\section{Characterization of plasticized poly(D,L-lactic acid) chewing gum}

\section{Texture profile analysis}

Texture profile analysis (TPA) is a test for analysing the textural properties of food, in which the samples are double-compressed using a texture analyser [14]. This method was first developed by General Foods Corporation in $1963[15,16]$. In this test, food samples are compressed twice in a motion that mimics biting and chewing to calculate many primary and secondary textural parameters, such as hardness, fracturability, springiness, cohesiveness, adhesiveness, gumminess, chewiness, and resilience [17]. The probe used for TPA was a 35-mm diameter (P/35) compression platen.

\section{Biodegradation studies}

To test the degradability of chewing gum bases, they were rolled into $2 \mathrm{~mm}$ thick slabs and placed on metal plates with dimensions $5 \mathrm{~cm} \times 25 \mathrm{~cm}$. The weathering was examined using the methods described in US Patent no. 7479293B2 $[16,18]$, which is similar to that in ISO 4892 , in which a wetting cycle is run for $2 \mathrm{~h}$ at $40{ }^{\circ} \mathrm{C}$, alternating with $6 \mathrm{~h}$ of illumination with a UV bulb at $45^{\circ} \mathrm{C}$. The cycle was run until an illumination period of $2500 \mathrm{~h}$ was achieved. The degradation of the chewing gum base is associated with the increase in chalking on the surface. The chalking on the surface of test slabs was visually assessed in each case before and after weathering and qualitatively assessed on a scale from 1 to 6 , where 1 denoted severe chalking and 6 denoted no chalking.

\section{Microstructure characterization}

To further investigate the morphological surface properties of the gum base, the microstructure of the gum base was examined using scanning electron microscopy (SEM) [19]. The MCGs with or without a plasticizer, sweetener coating, and drying were fixed on aluminium stubs and examined at a magnification of $120 x$ through a Philips scanning electron microscope, model 30 at an accelerating voltage of $5 \mathrm{kV}$ [20].

\section{In vitro drug release}

To examine the drug release in vitro, a modified chewing apparatus was fabricated to mimic human chewing. The device is registered as application/design number: 260364, journal number 34/2015, under the Controller General of Patents, Designs and Trademarks, Department of Industry Policy and Promotion, Ministry of Commerce, Government of India [21]. A schematic of the modified in vitro chewing machine is presented in Figure 1. It has functions similar to those of the chewing apparatus developed by Kvist et al [22], which has a single chewing module comprising a stainless steel test cell on which two vertically oriented pistons are mounted, serving as upper and lower chewing surfaces, respectively [16]. The cell is filled with 25-50 $\mathrm{mL}$ of aqueous medium, and the chewing gum is loaded onto the lower chewing surface. The lower surface moves up and down, and the upper surface has a motor that twists to masticate the chewing gum and to agitate the test medium.

The distance between chewing surfaces, frequency of the strokes, and the angle of twisting can be adjusted as required [22]. A chamber in thermal contact with the lower surface provides thermostat.

\section{Sensory evaluation}

The future commercialization of plasticized poly(D,L-lactic acid) caffeine chewing gums depends on consumers' response. Sensory evaluation methods were adopted in this study to investigate the attributions of the poly(D,L-lactic acid) caffeine chewing gum. 


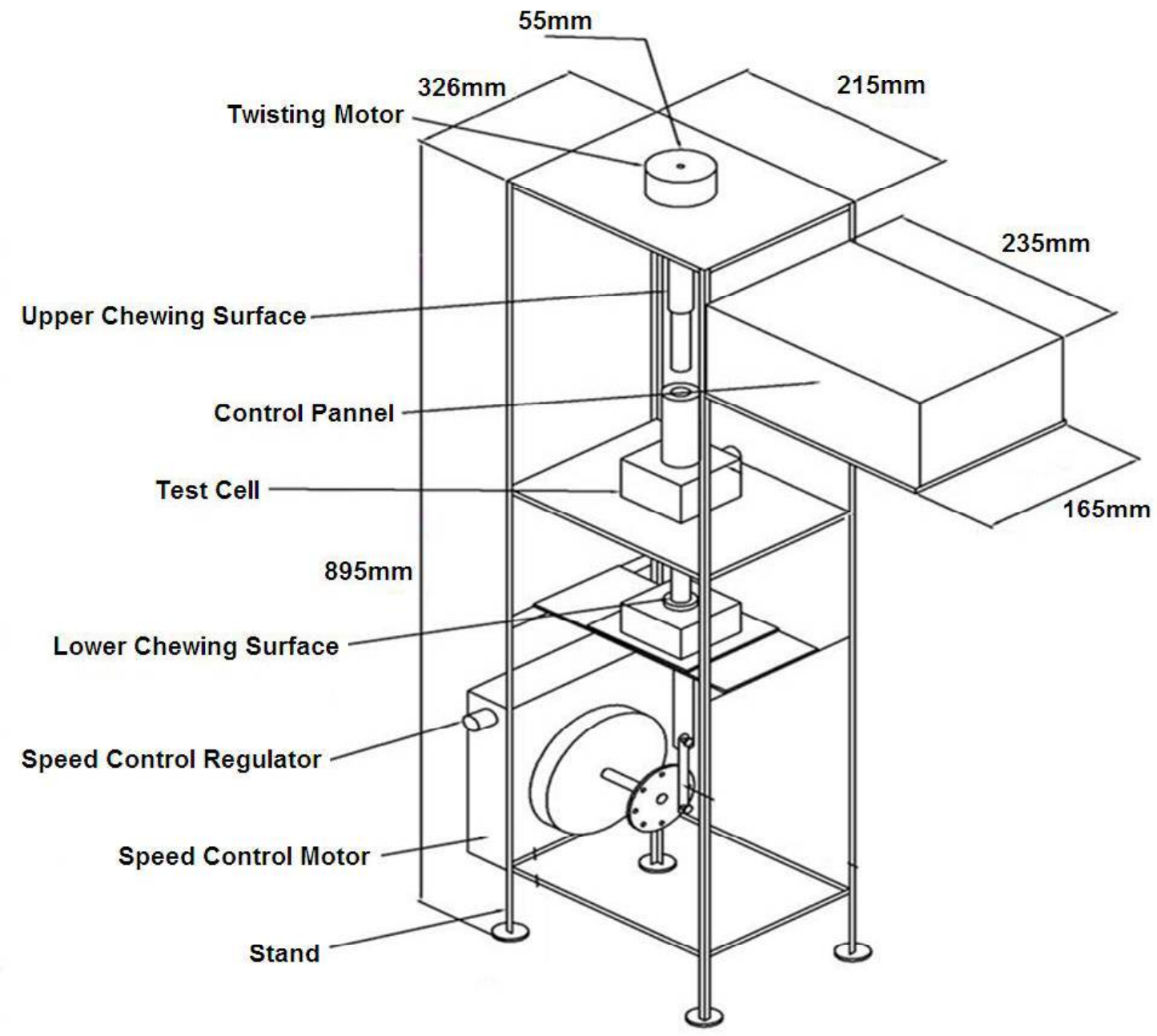

Figure 1: In vitro chewing apparatus

The sensory evaluation helps to identify critical attributes that must be considered during product and process development. The sensory evaluation of the poly(D,L-lactic acid) caffeine chewing gum with a low-calorie sweetener was performed to detect any variation in the sensory attributes of the chewing gum resulting from the incorporation of the sweetener coating solution $(1-6 \% \mathrm{w} / \mathrm{w})$ containing artificial sweeteners [23]. The evaluation was performed in a well-lit room, which was free from any odour. For the evaluation of appearance and colour, panel booths were uniformly illuminated with special specific daylight bulbs. A team of three men and three women was selected based on their sensitivity to sweetness and trained to identify and quantify the sensory characteristic [16] of the plasticized poly(D,L-lactic acid) caffeine chewing gum. Informed written consent was obtained from all participants. The sensory evaluation was conducted on the basis of the 9-point hedonic scale, in which 9 denoted 'like extremely' and 1 denoted 'dislike extremely' [16]. The plasticized poly(D,L-lactic acid) caffeine chewing gum was graded with a low-calorie sweetener against a control with $6 \% \mathrm{w} / \mathrm{w}$ sucrose [23] for taste and sweetness, consistency, softness, and overall acceptability.

\section{Statistical analysis}

Data were analysed using one-way analysis of variance followed by a least significant difference test for multiple sample comparison by using Sigma Stat (version 3.5, Systat Software Inc., Chicago, IL, USA). Statistical significance was set at $p<0.05$.

\section{RESULTS}

\section{Coating firmness}

Table 1 summarizes the coating firmness data for plasticized poly(D,L-lactic acid) chewing gum formulations (MCG-1 to MCG-10). Coating firmness was determined with a cylindrical aluminium probe $(\mathrm{P} / 3)$ with a diameter of $3 \mathrm{~mm}$. The results are shown in Table 1. 


\section{Texture profile}

Table 2 presents TPA parameters [16] of plasticized poly(D,L-lactic acid) chewing gum formulations (MCG-1 to MCG-10). The reference standard for determining TPA values was the Military Energy Gum (Marketright Inc., IL, USA). The control standard was a branded chewing gum named Chicza manufactured by Mayan Rainforest Company, Suffolk, UK [16].

\section{Biodegradation}

Biodegradation results of MCG-1 to MCG-10 formulations are presented in Table 3. MCG-1 and MCG-7, which were plasticized using triacetin and glycerol, exhibited significant biodegradation with a chalking score of 1 and 2 , respectively.

Table 1: Coating firmness $(\mathrm{kg})$ for plasticized poly $(\mathrm{D}, \mathrm{L}$-lactic acid) chewing gum

\begin{tabular}{lcccccc}
\hline $\begin{array}{l}\text { Formulation } \\
\text { code }\end{array}$ & Coating-1 & Coating-2 & Coating-3 & Coating-4 & Coating-5 & Coating-6 \\
\hline MCG-1 & 0.755 & 0.916 & 0.937 & 1.470 & 1.464 & 1.871 \\
MCG-2 & 0.898 & 0.910 & 1.176 & 1.140 & 1.493 & 1.887 \\
MCG-3 & 0.868 & 1.051 & 1.086 & 1.095 & 1.060 & 1.664 \\
MCG-4 & 0.896 & 0.912 & 1.284 & 1.288 & 1.404 & 1.482 \\
MCG-5 & 0.588 & 0.658 & 0.965 & 0.779 & 0.941 & 1.061 \\
MCG-6 & 0.791 & 0.859 & 0.746 & 1.039 & 1.419 & 1.378 \\
MCG-7 & 0.797 & 0.836 & 0.877 & 0.957 & 0.979 & 1.384 \\
MCG-8 & 0.822 & 1.010 & 1.043 & 1.177 & 1.255 & 1.350 \\
MCG-9 & 0.799 & 0.882 & 1.028 & 1.289 & 1.116 & 1.269 \\
MCG-10 & 0.740 & 0.800 & 0.860 & 0.769 & 1.362 & 1.501 \\
Avg. & 0.795 & 0.883 & 1.002 & 1.100 & 1.249 & 1.484 \\
SD & 0.090 & 0.109 & 0.158 & 0.224 & 0.208 & 0.260 \\
\hline
\end{tabular}

Table 2: TPA values of various plasticized poly(D,L-lactic acid) chewing gum formulations

\begin{tabular}{|c|c|c|c|c|c|c|c|}
\hline Test ID & $\begin{array}{l}\text { Hardness } \\
\text { (g) }\end{array}$ & $\begin{array}{c}\text { Adhesiveness } \\
\text { (g.s) }\end{array}$ & Springiness $^{*}$ & Cohesiveness* & Gumminess $^{\#}$ & $\begin{array}{c}\text { Chewiness } \\
\text { (g) }\end{array}$ & Resilience* $^{\star}$ \\
\hline$\overline{\text { TPA,MCG-1 }}$ & 3750.523 & -51.13 & 0.966 & 0.364 & 1580.88 & 1526.23 & 0.249 \\
\hline TPA,MCG-2 & 4143.839 & - & 0.316 & 0.215 & 1021.71 & 332.887 & 0.203 \\
\hline TPA,MCG-3 & 4347.27 & - & 0.321 & 0.213 & 844.839 & 301.691 & 0.177 \\
\hline TPA,MCG-4 & 4091.319 & - & 0.304 & 0.211 & 910.349 & 312.215 & 0.162 \\
\hline TPA,MCG-5 & 4019.025 & - & 0.308 & 0.214 & 915.739 & 316.362 & 0.165 \\
\hline TPA,MCG-6 & 4244.023 & - & 0.326 & 0.211 & 929.163 & 302.513 & 0.167 \\
\hline TPA,MCG-7 & 3963.121 & -21.12 & 0.314 & 0.210 & 926.170 & 268.425 & 0.165 \\
\hline TPA,MCG-8 & 4567.104 & - & 0.341 & 0.215 & 1070.635 & 314.450 & 0.199 \\
\hline TPA,MCG-9 & 4116.321 & - & 0.326 & 0.217 & 995.414 & 340.061 & 0.182 \\
\hline TPA,MCG-10 & 4054.287 & - & 0.345 & 0.225 & 903.169 & 301.122 & 0.166 \\
\hline Coef.var & 0.065 & -42.13 & 0.031 & 0.034 & 0.070 & 0.065 & 1.597 \\
\hline SD & 221.870 & 21.220 & 0.203 & 0.047 & 211.78 & 385.11 & 0.027 \\
\hline Avg. & 4141.971 & -36.125 & 0.386 & 0.229 & 1009.800 & 431.59 & 0.183 \\
\hline
\end{tabular}

Table 3: Biodegradation results

\begin{tabular}{lcc}
\hline $\begin{array}{l}\text { Formulation } \\
\text { code }\end{array}$ & $\begin{array}{c}\text { Chalking } \\
\text { before } \\
\text { weathering }\end{array}$ & $\begin{array}{c}\text { Chalking } \\
\text { after weathering } \\
\text { (mean } \pm \text { SD, } \boldsymbol{n}=6)\end{array}$ \\
\hline MCG-1 & 6 & $1 \pm 0.10$ \\
MCG-2 & 6 & $5 \pm 0.18$ \\
MCG-3 & 6 & $6 \pm 0.12$ \\
MCG-4 & 6 & $3 \pm 0.17$ \\
MCG-5 & 6 & $5 \pm 0.12$ \\
MCG-6 & 6 & $6 \pm 0.11$ \\
MCG-7 & 6 & $2 \pm 0.12$ \\
MCG-8 & 6 & $5 \pm 0.13$ \\
MCG-9 & 6 & $4 \pm 0.04$ \\
MCG-10 & 6 & $3 \pm 0.12$ \\
\hline
\end{tabular}

\section{Microstructure characteristics}

The SEM images in Figures 2 and 3 reveal that formulations with a plasticizer, sweetener coating, and drying had smoother surfaces compared with those without a plasticizer, sweetener coating, and drying. Overall, the SEM results demonstrated that the addition of plasticizers, coating with sweetener, and drying can increase the acceptance of MCGs among patients because of the aesthetic appearance of these MCGs. 


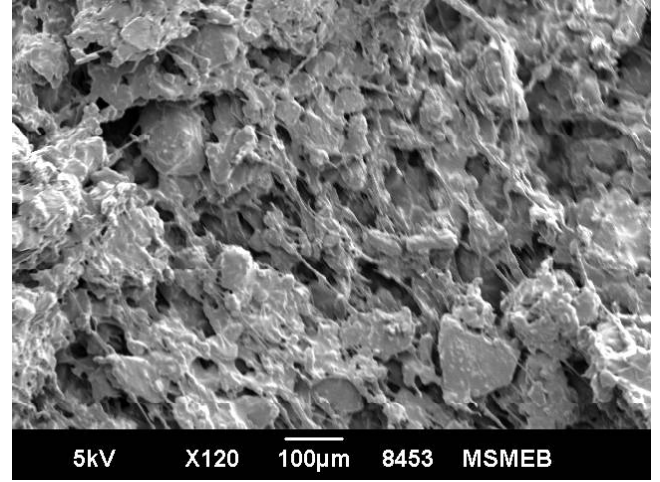

Figure 2: SEM image of MCG-1 formulation before coating and drying

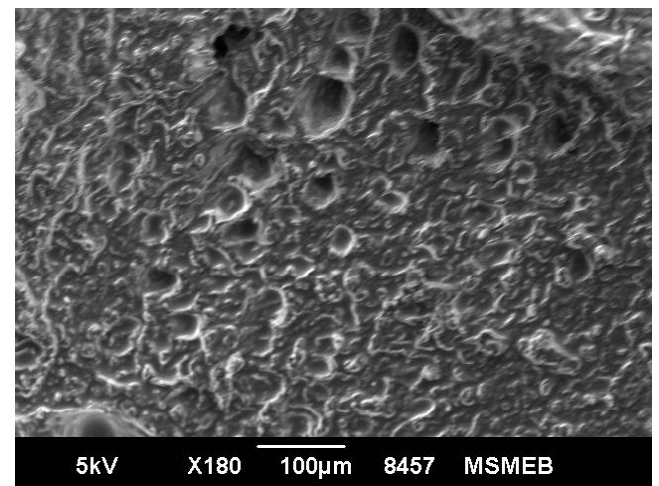

Figure 3: SEM image of MCG-1 formulation after coating and drying

\section{In vitro drug release}

Table 4 presents the drug release profiles of MCG-1 to MCG-10 formulations. With a mean chewing time of $15 \mathrm{~min}$, the highest drug releases of $87 \%$ and $80 \%$ were observed in the MCG-1 and MCG-9 formulations, which were plasticized using triacetin and triethyl citrate, respectively. MCG-5 formulation, in which soya oil was used as a plasticizer, exhibited the lowest drug release of $57 \%$ among various formulations.

\section{Sensory properties}

The sensory evaluation results in Table 5 suggest the feasibility of creating commercial plasticized poly(D,L-lactic acid) caffeine chewing gum formulations. Coating three solution used for coating MCG was similar to control and possessed the same required taste, consistency, and softness. However, the overall acceptability score of the plasticized poly(D,L-lactic acid) caffeine chewing gum was lower $(p<0.05)$ than that of sucrose, which was used as a control.

Table 4: In vitro drug release with the following adjustments: twisting angle, $20^{\circ}$; RPM 60 strokes/min; distance, $1.5 \mathrm{~mm}$; and temperature, $37.5^{\circ} \mathrm{C}$

\begin{tabular}{|c|c|c|c|c|c|c|c|c|c|c|}
\hline \multirow{2}{*}{$\begin{array}{l}\text { Time } \\
\text { interva } \\
\text { (min) }\end{array}$} & \multicolumn{10}{|c|}{$\%$ Drug release ${ }^{\#}$} \\
\hline & MCG-1 & MCG-2 & MCG-3 & MCG-4 & MCG-5 & MCG-6 & MCG-7 & MCG-8 & MCG-9 & MCG-10 \\
\hline 5 & $74 \pm 0.12$ & $45 \pm 0.10$ & $48 \pm 0.16$ & $69 \pm 0.4$ & $43 \pm 0.13$ & $44 \pm 0.12$ & $72 \pm 0.14$ & $47 \pm 0.13$ & $71 \pm 0.17$ & $44 \pm 0.12$ \\
\hline 10 & $80 \pm 0.15$ & $54 \pm 0.11$ & $59 \pm 0.10$ & $74 \pm 0.16$ & $51 \pm 0.11$ & $55 \pm 0.19$ & $77 \pm 0.12$ & $55 \pm 0.11$ & $75 \pm 0.11$ & $53 \pm 0.16$ \\
\hline 15 & $87 \pm 0.18$ & $59 \pm 0.09$ & $65 \pm 0.14$ & $77 \pm 0.18$ & $57 \pm 0.15$ & $60 \pm 0.11$ & $82 \pm 0.13$ & $62 \pm 0.11$ & $80 \pm 0.13$ & $59 \pm 0.19$ \\
\hline 20 & $93 \pm 0.11$ & $67 \pm 0.13$ & $73 \pm 0.17$ & $81 \pm 0.17$ & $64 \pm 0.13$ & $68 \pm 0.10$ & $89 \pm 0.19$ & $71 \pm 0.10$ & $85 \pm 0.17$ & $66 \pm 0.14$ \\
\hline 25 & $97 \pm 0.09$ & $73 \pm 0.11$ & $79 \pm 0.19$ & $86 \pm 0.15$ & $70 \pm 0.13$ & $75 \pm 0.11$ & $94 \pm 0.11$ & $76 \pm 0.11$ & $92 \pm 0.10$ & $71 \pm 0.13$ \\
\hline
\end{tabular}

Table 5: Sensory evaluation of plasticized poly(D,L-lactic acid) chewing gum

\begin{tabular}{lccccccc}
\hline Characteristic & Control & Coating 1 & Coating 2 & Coating 3 & Coating 4 & Coating 5 & Coating 6 \\
\hline $\begin{array}{l}\text { Taste and } \\
\text { sweetness }\end{array}$ & $09 \pm 0.1^{\mathrm{a}}$ & $06 \pm 0.1^{\mathrm{b}}$ & $06.5 \pm 0.3^{\mathrm{b}}$ & $08 \pm 0.5^{\mathrm{a}}$ & $07 \pm 0.5^{\mathrm{b}}$ & $07 \pm 0.5^{\mathrm{b}}$ & $07.5 \pm 0.5^{\mathrm{b}}$ \\
Consistency & $09 \pm 0.2^{\mathrm{a}}$ & $06 \pm 0.2^{\mathrm{b}}$ & $06.5 \pm 0.8^{\mathrm{b}}$ & $07 \pm 0.5^{\mathrm{b}}$ & $07 \pm 0.7^{\mathrm{b}}$ & $07 \pm 0.6^{\mathrm{b}}$ & $07.0 \pm 0.4^{\mathrm{b}}$ \\
Softness & $09 \pm 0.6^{\mathrm{a}}$ & $07 \pm 0.6^{\mathrm{b}}$ & $07 \pm 0.5^{\mathrm{b}}$ & $07.5 \pm 0.4^{\mathrm{b}}$ & $07.5 \pm 0.2^{\mathrm{b}}$ & $07.5 \pm 0.1^{\mathrm{b}}$ & $07.5 \pm 0.8^{\mathrm{b}}$ \\
$\begin{array}{l}\text { Overall } \\
\text { acceptability }\end{array}$ & $09 \pm 0.7^{\mathrm{a}}$ & $07 \pm 0.5^{\mathrm{b}}$ & $07 \pm 0.3^{\mathrm{b}}$ & $09 \pm 0.6^{\mathrm{a}}$ & $07.5 \pm 0.2^{\mathrm{b}}$ & $07.5 \pm 0.1^{\mathrm{b}}$ & $07.5 \pm 0.1^{\mathrm{b}}$ \\
\hline $\begin{array}{l}\text { Means in each row with different superscripts (a, b) are significantly different (least significant } \\
\text { difference test, } p<0.05 \text { ) from each other. Data are presented as mean } \pm \text { standard error mean }(n=6)\end{array}$
\end{tabular}

\section{DISCUSSION}

MCGs are made of water-insoluble and nonbiodegradable synthetic rubber. The stickiness and adhesive texture [14] of a gum makes it impossible to be removed from the site of adherence. The high cleaning cost of environmental pollution caused by synthetic gums results in demands for the development of biodegradable chewing gums, which are palatable and have an appropriate texture, reasonable shelf life, and long-lasting flavour. 
Wakefulness is necessary for individuals who work late at night such as those in the emergency services. Through a caffeine chewing gum, rapid doses of caffeine can be delivered within few minutes of chewing.

Aslani et al [11] prepared 22 formulations of the caffeine chewing gum by using four synthetic gum bases and evaluated their organoleptic properties at different stages of formulations. Henry et al [24] demonstrated that the caffeine gum has a slow drug release rate after 40 min of chewing, a condition in which $97 \%$ of drug has been already released. In previous studies, encapsulating the caffeine particles with zein, shellac, and hydroxypropylmethyl cellulose [25] caused changes in the physical properties of caffeine.

Military Energy Gum (Marketright Inc.) was used as the reference standard. The firmness of the third coating solution was $1.002 \mathrm{~kg}$, which is similar to that of the reference chewing gum. Moreover, the coating firmness increased from 0.795 to $1.484 \mathrm{~kg}$ with the increase in sweetener concentration. The coating operation should be performed immediately after formulation to prevent the migration of water from the core of the gum to the surface during storage.

The results of TPA by using a $35-\mathrm{mm}$ probe indicated that the peak load required to deform MCGs (MCG-1 to MCG-10) was $4141.97 \mathrm{~g}$. The MCGs deformed and then aggregated together to form a chewable gum mass during the test. MCG-1 and MCG-7 with triacetin and glycerol as plasticizers exhibited adhesiveness values of -51.13 and $-21.12 \mathrm{~g} \cdot \mathrm{s}$, respectively. During storage, the plasticizer of the chewing gum gets evaporated, and the chewing mass gets entrapped in a sponge, which presents the textural characteristic to the chewing gum. MCG3 and MCG-6 with PEG-600 and sunflower oil as plasticizers, respectively, had a biodegradation score of 6 , which represents no chalking and no biodegradation. Moreover, the biodegradation data were consistent with TPA data. The high biodegradation values of 1 and 2 in MCG-1 and MCG-7 formulations, respectively, could be because of their low hardness values of 3750.523 and $3963.121 \mathrm{~g}$, respectively, indicating severe chalking on the gum surface.

SEM images captured the plasticized poly(D,Llactic acid) gum base before and after coating and drying for $1 \mathrm{~h}$ at $50{ }^{\circ} \mathrm{C}$. The images revealed a spongy material with a highly porous surface and large ridge-like areas that might be created because of the shearing and drying of the samples. Moreover, MCG-1 formulation exhibited a smoother surface compared with the formulations without coating. Thus, MCG-1 formulation may receive a higher patient acceptance because of its aesthetic surface property.

A modified in vitro chewing apparatus was used to determine in vitro drug release. Among all plasticized poly(D,L-lactic acid) caffeine MCG formulations, MCG-1 with triacetin as the plasticizer, exhibited the highest drug release of $97 \%$ after $25 \mathrm{~min}$ of chewing, which indicates that the drug was uniformly distributed in the gum matrix. A study by Aslani and Jalilian demonstrated that 20 and $50 \mathrm{mg}$ [11] of caffeine MCGs released $88 \%$ and $89 \%$ of their drug after $30 \mathrm{~min}$, respectively. The drug release from the MCG depends on the chewing speed, chewing intensity, and the amount of saliva produced during chewing [11]. We observed a drug release pattern of $43-74 \%$ after $5 \mathrm{~min}, 57$ - $87 \%$ after $15 \mathrm{~min}$, and $70-97 \%$ after $25 \mathrm{~min}$ of kneading by a modified in vitro chewing apparatus for various plasticized poly(D,L-lactic acid) caffeine MCG formulations. A study conducted by Henry et al [24] on the drug release of caffeine chewing gums demonstrated a drug release of $88 \%$ after $20 \mathrm{~min}$ and $97 \%$ after $40 \mathrm{~min}$.

For MCGs containing different blends of sweeteners (1-6\% w/w), neotame was used as an artificial sweetener, which completely masked the bitter taste of caffeine. The high score for taste, consistency, and softness of the control could be because of its sucrose content. Sucrose is responsible for the binding effect in MCGs and helps to form a network of microfibrils, which creates a binding effect in the product. Sensory evaluation results revealed that the low-calorie sweetener neotame can be beneficial to consumers because it provides few empty sugar calories.

\section{CONCLUSION}

The study findings indicate the feasibility of formulating MCG with plasticized poly(D,L-lactic acid) as the gum base and a combination of sweeteners as the taste enhancer. Plasticized poly(D,L-lactic acid) caffeine chewing gums possess the advantages of synthetic chewing gums as well as additional advantages such as effective and efficient caffeine delivery to control fatigue. Furthermore, triacetin and glycerol used as plasticizers are functional and edible, producing a desirable gum texture, and are biodegradable. 


\section{DECLARATIONS}

\section{Acknowledgement}

The authors wish to acknowledge C.S.I.R, New Delhi, India for providing SRF, and M.P.C.S.T Bhopal (M.P.) for funding the purchase of a texture analyzer.

\section{Conflict of Interest}

No conflict of interest associated with this work.

\section{Contribution of Authors}

The authors declare that this work was done by the authors named in this article and all liabilities pertaining to claims relating to the content of this article will be borne by them.

\section{Open Access}

This is an Open Access article that uses a funding model which does not charge readers or their institutions for access and distributed under the terms of the Creative Commons Attribution License (http://creativecommons.org/licenses/by/ 4.0) and the Budapest Open Access Initiative (http://www.budapestopenaccessinitiative.org/rea d), which permit unrestricted use, distribution, and reproduction in any medium, provided the original work is properly credited.

\section{REFERENCES}

1. European Pharmacopeia 2010. Directorate for quality of medicines, Council of Europe, $p 709$.

2. Shah KR, Mehta TA. Medicated Chewing Gum- A Mobile Oral Drug Delivery System. Int J Pharm Tech Res 2014; 6(1): 35-48.

3. Shojaei A. Buccal mucosa as a route for systematic drug delivery. J Pharm Sci 1998; 1: 15-30.

4. Madhav NV, Shakya AK, Shakya $P$, Singh $K$. Orotransmucosal drug delivery systems: A review. J Control Release 2009; 24: 239-247.

5. Grijpma DW, Laimbiick GJF, Pennings $A A J$ and $N$ org. Biodegradable chewing gum. Patent no. US 5672367, USA, 30/09/1997.

6. Weisheng $\mathrm{LI}$, Montelair NJ. Biodegradable chewing gum bases including plasticized poly(d,l-lactic acid) and copolymers thereof. Patent no. US 6613363 B1, USA, 02/09/2003.

7. Yang $X$, Wang G, Zhang $X$. Release kinetics of catechins from chewing gum. J Pharma Sci 2004; 93: 293-299.

8. Rafiei S, Aslani A. Design, formulation and evaluation of nicotine chewing gum. Adv Biomed Res 2012; 1: 57-62.

9. Rassing MR. Chewing gum as drug delivery system. Adv Drug Deliv Rev1994; 13: 89-121.
10. Nehlig A, Daval JL, Debry G. Caffeine and the central nervous system: Mechanisms of action, biochemical, metabolic and psycho stimulant effects. Brain Res Rev 1992; 17: 139-170.

11. Aslani A, Jalilian F. Design, formulation and evaluation of caffeine chewing gum. Adv Biomed Res 2013; 2: 72-79.

12. Mehta F, Trivedi $P$. Formulation and characterization of natural biodegradable chewing gum. Int $J$ Pharm Tech Res 2012; 4(3): 889-900.

13. Zyck DJ, Greenberg MJ, Barkalow DG, Marske SW, Schnell PG, Mazzone P, Hammomd JE, Witkewitz DL, Sitler DJ, Petrocelli RM: 17/06/2003. Coated chewing gum product containing an antigas agent. Patent no: US 6579545B2.USA.

14. Mehta F, Rajagopalan R, Trivedi P. Formulation and texture characterization of environment friendly chewing gum. Int J Pharm Tech Res 2013; 5(1): 222-232.

15. Bourne MC. Texture profile analysis. Food Technol 1978; 32: 62-66.

16. Mehta FM, Trivedi P. Formulation and characterization of biodegradable medicated chewing gum delivery system for motion sickness using corn zein as gum former. Trop J Pharm Res 2015; 14(5): 753-760.

17. Sozer N, Kaya A. The effect of cooking water composition on textural and cooking properties of spaghetti. Int J Food Prop 2008; 11(2): 351-362.

18. Grawe R, Wimmer T. Degradable chewing gum bases and method of making. Patent no: US 7479293B2, USA, 20/01/2009.

19. Paradkar M, Gajra B, Patel B. Formulation development and evaluation of medicated chewing gum of antiemetic drug. Saudi Pharm J 2016; 24(2): 153-164.

20. Kotarba A, Adamski G, Sojka Z, Mariadassou GD, Pettersson JB. In situ monitoring of bare and k-doped Mo2C catalyst surface depassivation based on emission of electrons and $K+$ ions. Appl Surf Sci 2006; 252(12): 4129-4137.

21. Indian design /patent status for design application number-260334 available on internet from https://ipindiaonline.gov.in/designapplicationstatus/desig nstatus.aspx

22. Kvist $C$, Andersson $S B$, Fors $S$, Wennergren $B$, Berglund $J$. Apparatus for studying in vitro drug release from medicated chewing gums. Int J Pharm 1999; 189: 57 65.

23. Arora S, Singh V P, Yarrakula S, Gawande $H$, Narendra K, Sharma V, Wadhwa BK, Tomer SK, Sharma GS. Textural and micro structural properties of burfi made with various sweeteners. J Food Sci 2007; 61(5): 10681072.

24. Tyrpin HT, Russell MP, Witkewitz DL, Johnson SS, Ream $R L$, Corriveau CL. Caffeine coated chewing gum product and process of making. Patent no US 644241B1, USA, 03/09/2002.

25. Ting R, Hsiao C. Press coated pulsatile drug delivery system for oral administration. Patent no: WO1999051209 A1, USA, 14/10/1999. 